- Artículo original de investigación •

\author{
elocation-id: eia.n2a02
}




\title{
Análisis de la aplicación de la ley del primer empleo en las pequeñas empresas constituidas en Sogamoso en el año 2013
}

\author{
Analysis of the application of the First \\ Employment Law in the small companies \\ incorporated in Sogamoso in 2013
}

Estefanía Cuartas-Salazar'; Claudia Hernández-Castellanos²

\section{Resumen}

La Ley de Formalización y Generación de Empleo (1429 del 29 de diciembre de 2010) está enfocada principalmente a los jóvenes menores de 28 años. A pesar de los incentivos que propone el Gobierno por medio de estas leyes que deben mostrar un incremento en las tasas de empleabilidad en las pequeñas empresas, en la ciudad de Sogamoso se observa que no se presenta esta dinámica en el sentido que los jóvenes menores de 28 años que son recién egresados se ven afectados a la hora de ofertar sus servicios, ya que las mismas pequeñas empresas demandan principalmente experiencia, requisito que estos recién egresados no cumplen. De la investigación que da origen a este artículo, compete el análisis de la aplicación de la presente ley en las pequeñas empresas constituidas en Sogamoso en el año 2013. Esta es una investigación de tipo exploratoria con un método analítico-deductivo. La población corresponde a las pequeñas empresas constituidas en el año 2013. La muestra se basó en una clasificación estratificada de la actividad económica de las pequeñas empresas de Sogamoso. Se concluye que del $100 \%$ de las pequeñas empresas creadas (10 empresas), el $50 \%$ aseguró acogerse a la ley (5 empresas), de las cuales solo el $20 \%$ (1) cumple la ley cabalmente.

Palabras claves: desempleo juvenil, experiencia, formalización, jóvenes.

\section{Abstract}

The Law for Formalization and Job Creation (1429 of December 29, 2010), also known as the First Employment Law, was mainly aimed at promoting the hiring of employees under 28 . The Government offered 
benefits through this law which were expected to result in an increase of employability rates among small enterprises. However, this dynamic is no longer observed in the city of Sogamoso, where individuals under 28 , recently graduated from college, are affected, since small companies require work experience, a requirement that these recent graduates do not meet. This paper analyses the application of this law in the small companies incorporated in Sogamoso in 2013. An exploratory research study was carried out with an analyticaldeductive method. The study population was composed of small companies incorporated in 2013. The sample was based on a stratified classification of the economic activity of the small companies of Sogamoso. The study concludes that $50 \%$ out of $100 \%$ of small companies incorporated (10 companies) claimed to rely on the law (5 companies), out of which only $20 \%$ (1) fully abides by it.

Keywords: youth unemployment, experience, formalization, youth.

\section{Introducción}

Sogamoso ha mostrado un desarrollo empresarial fuerte desde aproximadamente los años 50 con empresas como: Paz del Río Votorantim Siderúrgia, Holcim, Cementos Argos, entre otras, alrededor de estas industrias se encuentran varias pequeñas y medianas empresas que se ubican en sectores como: el industrial, minero, comercial, de transportes, de construcción, etc. que contribuyen al fortalecimiento y crecimiento económico de la ciudad.

El sector también se ha visto influenciado a lo largo del tiempo por la normatividad con que cuentan las PYMES en Colombia tales como: la Ley 590 de 2000, conocida como Ley MIPYMES y sus modificaciones (Ley 905 de 2004) llamada de PYMES, 1014 de 2006 de fomento a la cultura de emprendimiento, 1258 de 2008 que crea la sociedad por acciones simplificadas (S.A.S), 1676 de 2013 «por la cual se promueve el acceso al crédito y se dictan normas sobre garantías mobiliarias», por último, la Ley de Formalización y Generación de Empleo (1429 del 29 diciembre de 2010) (ley del primer empleo).

La ley del primer empleo está enfocada principalmente a los jóvenes menores de 28 años (madres cabeza de familia, personas en situación de desplazamiento, en proceso de integración o en condiciones de discapacidad, mujeres mayores de 40 años) para garantizar el acceso al mundo laboral, al acogerse a esta ley se formulan diversos incentivos para los empleadores, entre los que destacan los tributarios. A pesar de los incentivos que propone el Gobierno por medio de estas leyes, deben mostrar un incremento en las tasas de empleabilidad en las pequeñas empresas. En la ciudad de Sogamoso se observa que no se presenta esta dinámica en el sentido que los jóvenes menores de 28 años que son recién egresados, se ven afectados a la hora de ofertar trabajo, ya que las mismas pequeñas empresas demandan principalmente experiencia, lo cual impide que quienes no la poseen queden por fuera. Por lo tanto, la situación es contradictoria, pues, ¿cómo van a tener experiencia? si las pequeñas empresas como principal foco de empleo en la ciudad no dan la oportunidad de trabajar. A partir de la investigación que da origen a este artículo, se busca analizar la aplicación de la ley del primer empleo en las pequeñas empresas constituidas en Sogamoso en el año 2013.

\section{Materiales y métodos}

La investigación se ejecutó gracias al cumplimiento de tres objetivos específicos: examinar el cumplimiento de la Ley de Formalización 
y Generación de Empleo (Ley 1429 de 2010) en las pequeñas empresas constituidas en Sogamoso en el año 2013; comparar la aplicación de la ley de formalización y generación de empleo (Ley 1429 de 2010) en una estratificación por actividad económica; identificar las pequeñas empresas creadas por cada sector económico durante el año 2013 en la ciudad de Sogamoso.

\section{Tipo de estudio}

Se trata de una investigación exploratoria, porque al presente no se han realizado estudios similares específicamente en la ciudad de Sogamoso durante el año 2013. Es también descriptiva, porque su principal objetivo fue dar a conocer el nivel de aplicación de la Ley de Formalización y Generación de Empleo (Ley 1429 de 2010) en las pequeñas empresas constituidas en Sogamoso en el año 2013.

La población objeto de estudio fueron todas las pequeñas empresas de Sogamoso constituidas en el año 2013. La muestra se basó en una clasificación estratificada de la actividad económica de las pequeñas empresas en la ciudad de Sogamoso.

\section{Métodos}

El método de investigación utilizado fue el analítico-deductivo. Analítico porque efectivamente se hizo un análisis de la aplicación de la Ley de Formalización y Generación de Empleo (Ley 1429 de 2010), y deductivo porque parte de un marco general, es decir, de la aplicación de la Ley de Formalización y Generación de Empleo (Ley 1429 de 2010) a nivel nacional y se dirige hacia un marco específico, o particular y delimitado como lo es «la aplicación de la Ley de Formalización y Generación de Empleo (Ley 1429 de 2010) en las pequeñas empresas constituidas en Sogamoso en el año 2013».

Las fuentes de información empleadas fueron primarias y secundarias. Las primarias, principalmente información de primera mano de las pequeñas empresas constituidas en el año 2013; las secundarias, datos suministrados por la Cámara de Comercio de la ciudad de Sogamoso, entre otros. Las técnicas de recolección de información a utilizar fueron: la encuesta y el instrumento el cuestionario.

La estratificación por actividad económica consistió en clasificar las empresas de acuerdo con su sector económico ya fuera industrial, construcción, comercial o servicios.

\section{Resultados}

La encuesta realizada a las pequeñas empresas creadas en el año 2013 de la ciudad de Sogamoso constó de 15 preguntas. Los resultados de la investigación fueron abordados en dos secciones: la primera mostró aspectos generales con respecto a la ley del primer empleo (requisitos esenciales para laborar en la empresa, personas laborando en situación de discapacidad, conocimiento de la ley, medio de comunicación, entre otros) y la segunda presentó el desarrollo o cumplimiento de los objetivos específicos. ${ }^{1}$

1 El número de pequeñas empresas que se crearon en el año 2013 de la ciudad de Sogamoso fueron trece (13) según datos entregados por la Cámara de Comercio, de las cuales tres (3) se encontraron inactivas al momento de realizar las encuestas. 


\section{Aspectos generales de la ley del primer empleo en las pequeñas empresas creadas en el año 2013 de la ciudad de Sogamoso}

La Ley 1429 de 2010, «ley del primer empleo», aborda seis grandes áreas de interés en materia laboral (Boletín del Observatorio del Mercado de Trabajo y la Seguridad Social, 2011) tales como: programas de desarrollo empresarial (artículo 3), reducción temporal en los costos de algunos requisitos legales que deben cumplir las pequeñas empresas durante sus primeros años de operación (artículos 4, 5, 6 y 7), incentivos para la generación de empleo de colectivos desfavorecidos laboralmente (artículos 9,10, 11 y 13), disposiciones acerca de las cooperativas de trabajo asociado (artículo 63), simplificación de trámites (artículos 17 a 23), creación del Sistema Nacional de Información sobre demanda de empleo (artículos 51 a 59).

A continuación, se muestra la representación gráfica de las diferentes preguntas y respuestas realizadas por medio de encuestas a las pequeñas empresas creadas en el año 2013 de la ciudad de Sogamoso.

\section{Sector económico: pequeñas empresas}

\section{Sector agropecuario}

Sector comercial

Sector construcción

Sector industrial

Sector servicios

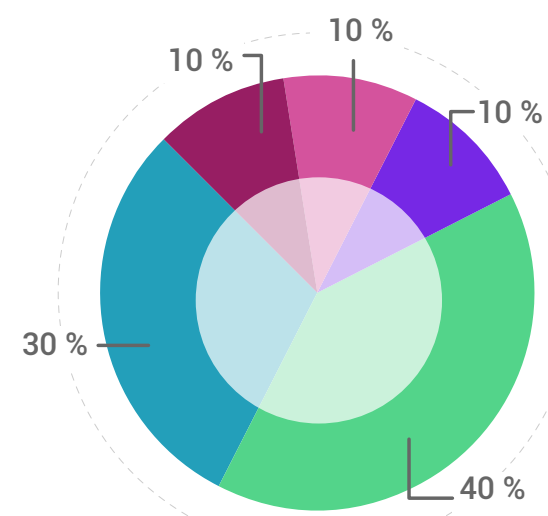

Figura 1. Sector económico en el que se ubica la empresa.

De acuerdo con la Figura 1, en el año 2013 el sector económico que más sobresalió en la creación de pequeña empresa fue el de la construcción con un $40 \%$ (4 empresas), seguido del industrial con un $30 \%$ (3 empresas), el de servicios con un $10 \%$ (1 empresa), el agropecuario con un $10 \%$ (1 empresa) y el comercial con un $10 \%$ (1 empresa). 


\section{Trabajadores que laboran en la empresa}

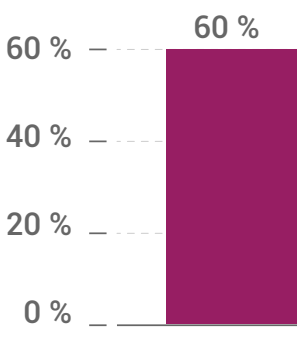

a. Entre 11 y 20

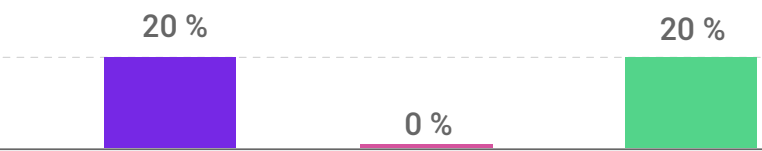

b. Entre 21 y 30

C.

d. a. Entre 11 y 20

b. Entre 21 y 30

c. Entre 31 y 40

d. Entre 41 y 50

Figura 2. Número de trabajadores que laboran en la empresa.

Los resultados que se muestran en la Figura 2 indican que el $60 \%$ de las pequeñas empresas ( 6 empresas) creadas en el año 2013 de la ciudad de Sogamoso en su mayoría cuentan con una planta de personal entre 11 a 20 trabajadores, seguido de un 20 \% (2 empresas) que aseguró tener entre 21 a 30 trabajadores y otro $20 \%$ (2 empresas) que afirmó tener entre 41 a 50 trabajadores.

\section{Requisitos esenciales para la vinculación de personal en la empresa}

a. Recomendaciones de los empleados

b. Condiciones académicas

c. Experiencia

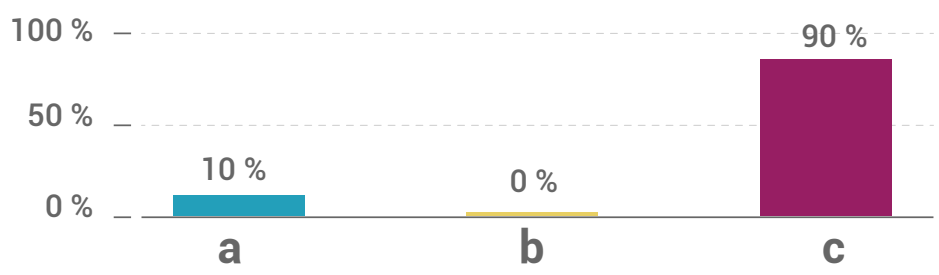

Figura 3. Requisitos para vinculación de personal en la empresa.

La Figura 3 muestra que el $90 \%$ de las pequeñas empresas ( 9 empresas) exige como requisito la experiencia para laborar en la empresa, mientras que un $10 \%$ ( 1 empresa) exige como requisito las recomendaciones de los empleados. 


\section{Conocimiento de la ley del primer empleo}

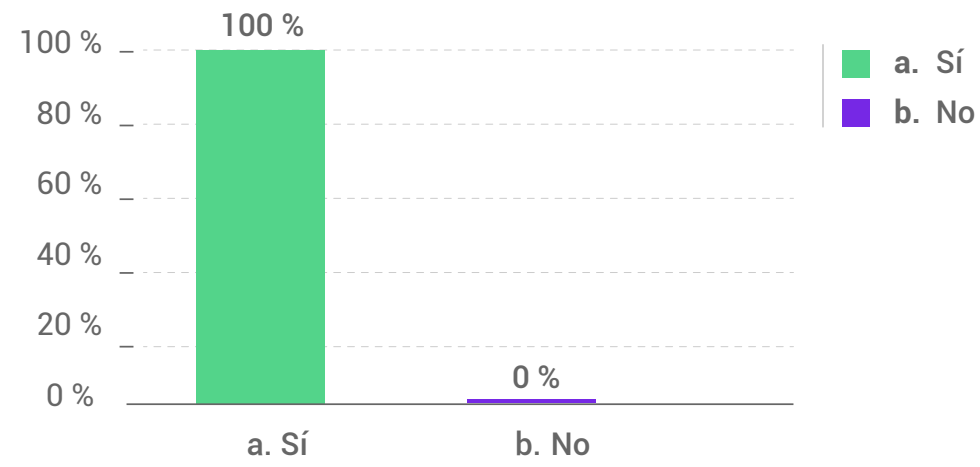

Figura 4. Conocimiento de la ley del primer empleo.

El $100 \%$ de las pequeñas empresas (10 empresas) de la ciudad de Sogamoso constituidas en el año 2013 aseguró conocer o por lo menos haber escuchado hablar acerca de la Ley de Formalización y Generación de Empleo (Ley 1429 del 29 de diciembre de 2010) mejor conocida como «ley del primer empleo» (Figura 4).

\section{Medio de comunicación - Ley del primer empleo}

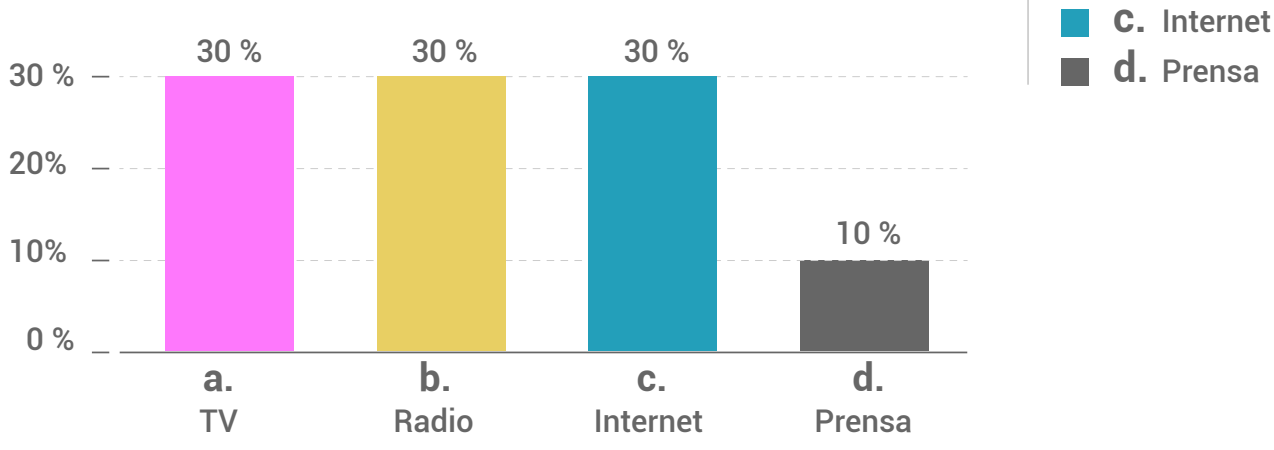

Figura 5. Medio de comunicación por el que la empresa fue informada acerca de la ley del primer empleo.

Los resultados expresados en la Figura 5 revelan que el $30 \%$ de las pequeñas empresas (3 empresas) se enteraron de la Ley de Formalización y Generación de Empleo (Ley 1429 del 29 de diciembre de 2010) mejor conocida como «ley del primer empleo» mediante la televisión, seguido de un $30 \%$ de pequeña empresa (3 empresas) que se enteró mediante la radio y otro $30 \%$ de pequeña empresa (3 empresas) que se enteró mediante la Internet, mientras que un $10 \%$ (1 empresa) a través de la prensa. 


\section{¿Acogida a la ley del primer empleo (Ley 1429 de 2010)?}

a. Sí
b. No

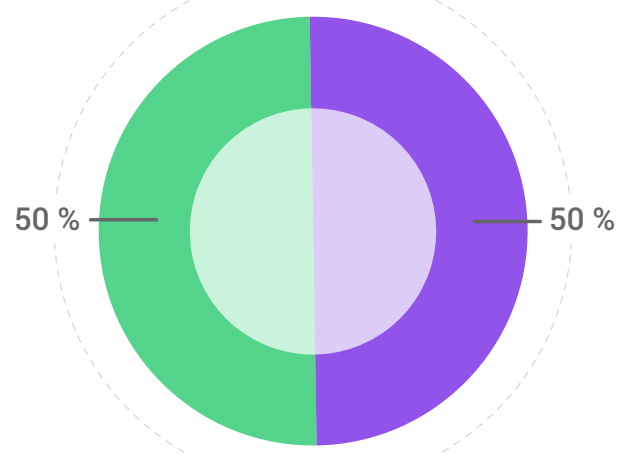

Figura 6. La empresa se encuentra acogida a la ley del primer empleo.

La Figura 6 muestra que el $50 \%$ de las pequeñas empresas (5 empresas) aseguró estar bajo la cobertura de la ley del primer empleo, mientras que el otro 50 \% de pequeñas empresas (5 empresas) afirmó no estar acogida o amparada bajo dicha ley.

\section{Beneficios tributarios que ofrece la ley del primer empleo}

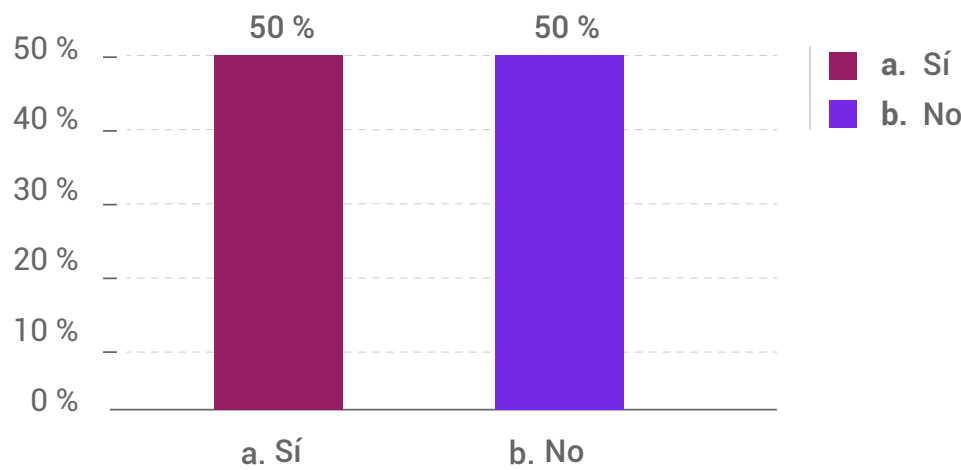

Figura 7. Beneficios tributarios que ofrece la ley del primer empleo.

Los resultados de la Figura 7 muestran a su vez el mismo resultado de la Figura 6, debido a que no es posible obtener beneficios de la ley si esta no se adopta por la empresa. De esta manera, la Figura 7 indica que el $50 \%$ de las pequeñas empresas ( 5 empresas) que se acogieron a la ley reciben dichos beneficios tributarios, mientras que el otro $50 \%$ de pequeñas empresas (5 empresas) no. 


\section{Contratación de jóvenes recién egresados de la universidad}

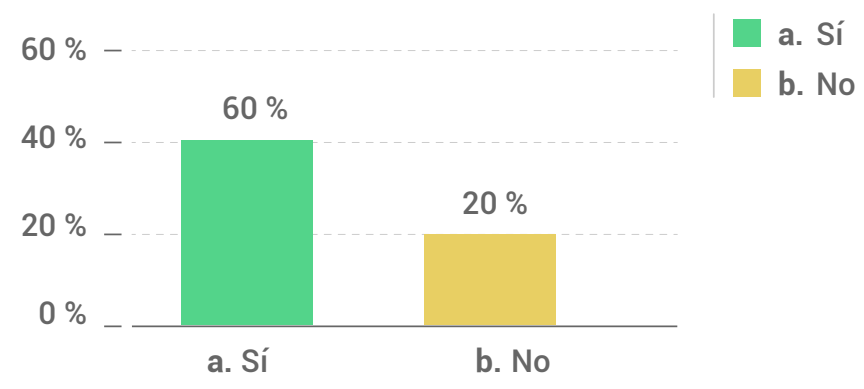

Figura 8. Contratación de jóvenes recién egresados de la universidad.

La Figura 8 muestra que el $40 \%$ de las pequeñas empresas (4 empresas) aseguró contratar jóvenes recién egresados de su carrera profesional, mientras que el 60 \% (6 empresas) afirmó no contratar jóvenes recién egresados de su carrera profesional específicamente por falta de experiencia.

\section{Jóvenes menores de 28 años que laboran en la empresa}

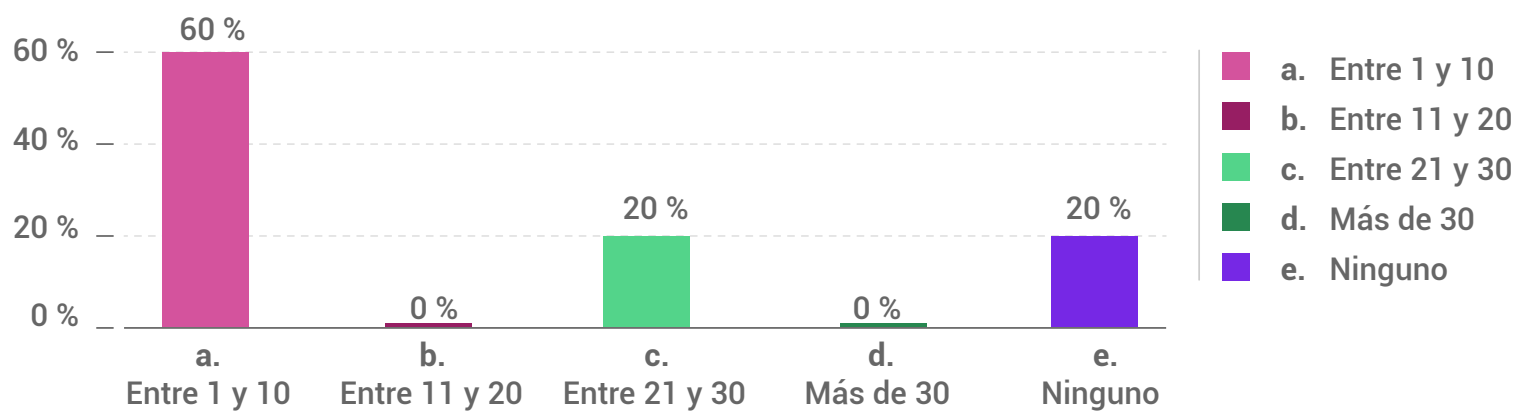

Figura 9. Jóvenes menores de 28 años que laboran en la empresa.

Los resultados mostrados en la Figura 9 indican que el $60 \%$ de las pequeñas empresas (6 empresas) afirmó que entre 1 y 10 es el rango de jóvenes que laboran en las empresas, seguido de un $20 \%$ ( 2 empresas) que expresó tener entre 21 y 30 jóvenes, mientras que un $20 \%$ de pequeñas empresas ( 2 empresas) aseguró no disponer de jóvenes menores de 28 años laborando en las empresas. 


\section{Personas en situación de discapacidad laborando en la empresa}

a. Sí

b. No

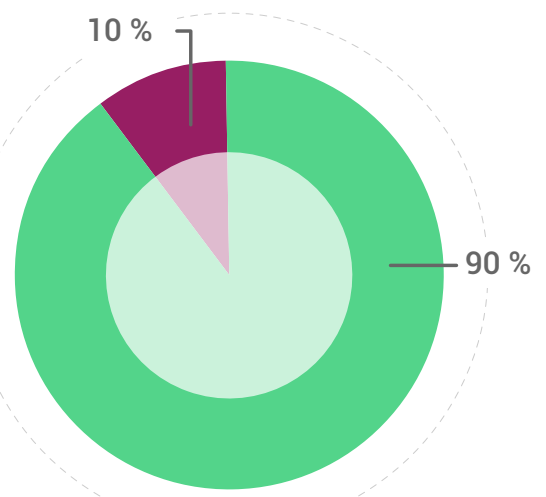

Figura 10. Personas en situación de discapacidad laborando en la empresa.

La Figura 10 muestra que el $90 \%$ de pequeñas empresas (9 empresas) afirmó no tener personas en situación de discapacidad laborando en la empresa, mientras que el $10 \%$ ( 1 empresa) aseguró tener este tipo de personas laborando en la empresa.

\section{Mujeres mayores de $\mathbf{4 0}$ años que laboran en la empresa}

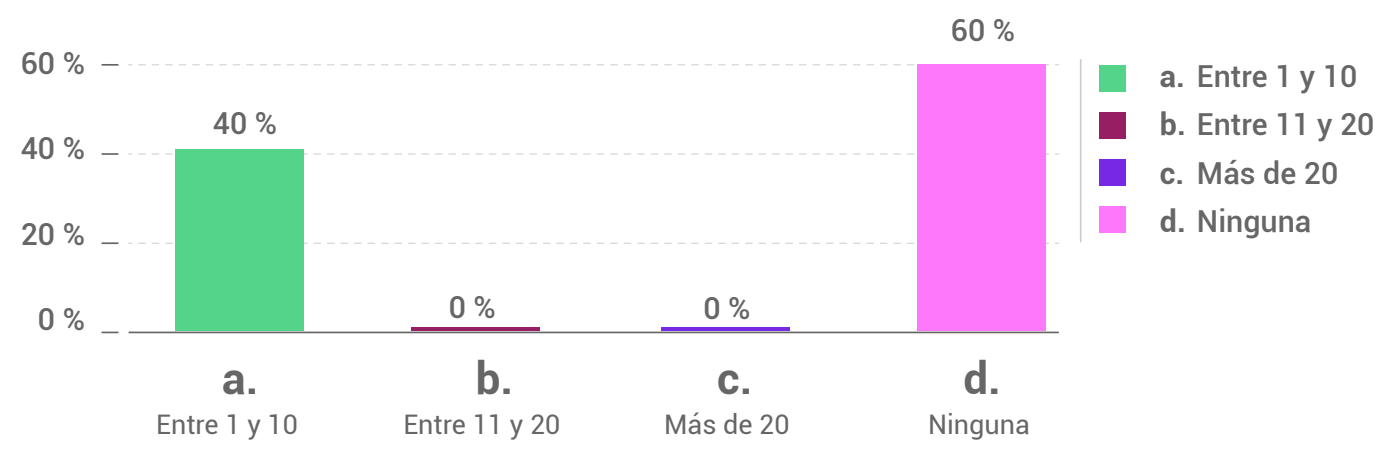

Figura 11. Mujeres mayores de 40 años que laboran en la empresa.

Los resultados mostrados por la Figura 11 indican que el $40 \%$ de las pequeñas empresas (4 empresas) tiene entre 1 y 10 mujeres mayores de 40 años laborando en la empresa, mientras que el $60 \%$ de las pequeñas empresas (6 empresas) aseguró no tener laborando a ninguna mujer mayor de 40 años en la empresa. 


\section{Eficacia de la ley del primer empleo}

a. Sí
b. No

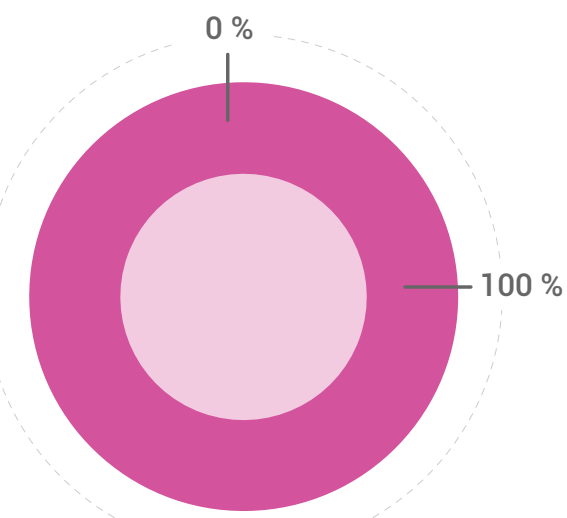

Figura 12. Eficacia de la ley del primer empleo.

La Figura 12 revela que el $100 \%$ de las pequeñas empresas (10 empresas) considera eficaz la ley del primer empleo para ayudar a la población juvenil. Sin embargo, la mitad de las empresas no se encuentra acogida a dicha ley, en consecuencia, no cumple con brindar la oportunidad de empleo a este segmento de la población.

\section{Nuevas medidas para la reducción del desempleo en la población juvenil}

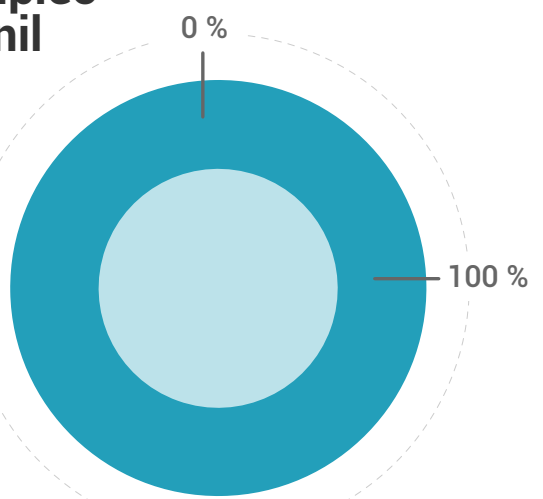

Figura 13. Nuevas medidas para la reducción del desempleo en la población juvenil.

La Figura 13 muestra que el $100 \%$ de las pequeñas empresas (10 empresas) consideran urgente adoptar nuevas medidas de carácter obligatorio para reducir el desempleo juvenil, debido a que la población juvenil no son el mañana del país, sino el hoy y el ahora. 


\section{Cumplimiento de los objetivos específicos de la investigación}

El primer objetivo específico plantea comparar la ley mediante estratificación por actividad económica. El segundo busca examinar el cumplimiento de la ley del primer empleo por parte de las pequeñas empresas $y$, el tercero, identificar las pequeñas empresas creadas según el sector económico correspondiente. Dicho lo anterior, a continuación, se mostrará la representación gráfica de los objetivos.

Comparar la aplicación de la ley de formalización y generación de empleo (Ley 1429 de 2010) en una estratificación por actividad económica

\section{Pequeñas empresas acogidas a la ley del primer empleo según la actividad económica}

Sí. Sector comercial

Sí. Sector construcción

Sí. Sector industrial

Sí. Sector servicios

No. Sector agropecuario

No. Sector construcción

No. Sector industrial

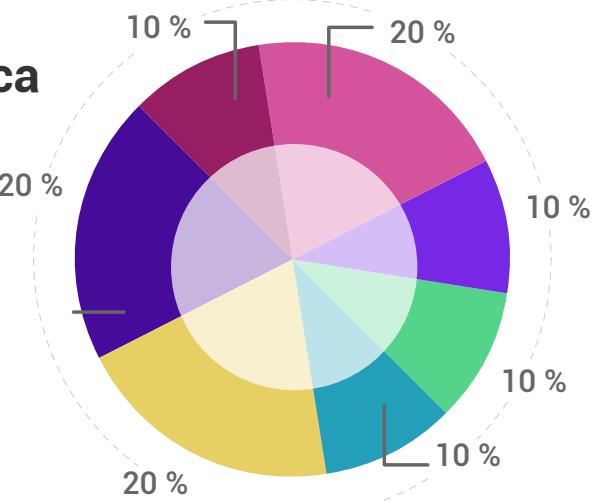

$20 \%$

Figura 14. Aplicación de la ley en una estratificación por actividad económica.

De acuerdo con los resultados mostrados por la Figura 14, existe un equilibrio entre las pequeñas empresas que se acogieron y aplicaron (sombreadas de color azul) la ley del primer empleo frente a las que no (sombreadas de color verde), es decir, el 50 \% (5 empresas) afirmó que sí, mientras el otro $50 \%$ (5 empresas) no. Las pequeñas empresas que se acogieron a la ley según la actividad económica están distribuidas así: 10 \% sector comercial ( 1 empresa), 20 \% sector construcción ( 2 empresas), $10 \%$ sector industrial ( 1 empresa), $10 \%$ sector servicios ( 1 empresa). Mientras el otro $50 \%$ de pequeñas empresas aseguró no haberse acogido a dicha ley y por tanto no aplicarla. Distribuido así: $20 \%$ sector industrial (2 empresas), 20 \% sector construcción (2 empresas), $10 \%$ sector agropecuario (1 empresa).

Examinar el cumplimiento de la Ley de Formalización y Generación de Empleo (Ley 1429 de 2010) en las pequeñas empresas constituidas en Sogamoso en el año 2013. 


\section{Cumplimiento de la ley del primer empleo por parte de las pequeñas}

Sí. Sector construcción

Sí. Sector industrial y comercial

No. Sector servicios y construcción

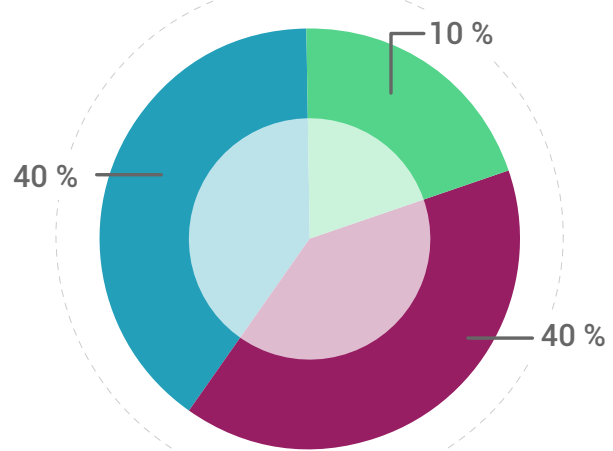

Figura 15. Cumplimiento de la ley del primer empleo.

La Figura 15 arroja unos resultados poco alentadores, ya que del $50 \%$ de pequeñas empresas ( 5 empresas) que aseguraron estar acogidas a la ley y recibir los beneficios que esta ofrece, solo el $20 \%$ de pequeñas empresas ( 1 empresa) perteneciente al sector de la construcción, según el análisis realizado, parece cumplir cabalmente la ley. El $40 \%$ de las pequeñas empresas (2 empresas), perteneciente el $20 \%$ al sector industrial y $20 \%$ al sector comercial, asegura cumplir la ley parcialmente, mientras que el $40 \%$ de las pequeñas empresas (2 empresas), perteneciente el $20 \%$ al sector servicios y el $20 \%$ al sector construcción, afirma no cumplir la ley pese a recibir los beneficios que ofrece la ley.

Identificar las pequeñas empresas creadas por cada sector económico durante el año 2013 en la ciudad de Sogamoso.

\section{Sector económico: pequeñas empresas}

Sector agropecuario

Sector comercial

Sector construcción

Sector industrial

Sector servicios

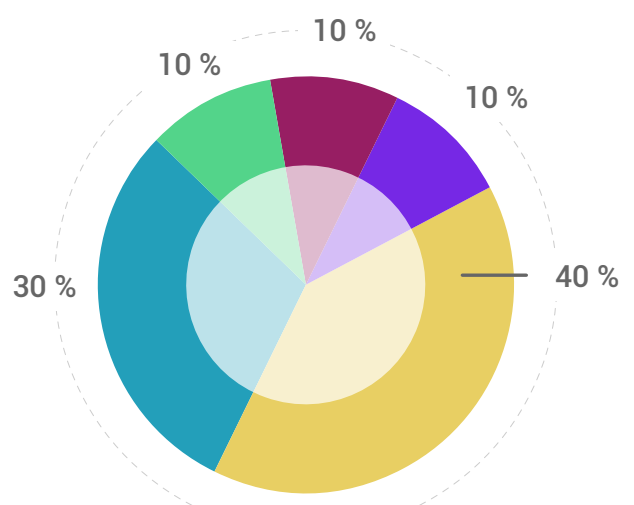

Figura 16. Pequeñas empresas creadas según el sector económico.

Los resultados de la Figura 16 muestran el número de pequeñas empresas creadas en el año 2013 por cada sector económico en la ciudad de 
Sogamoso. Distribuido así: sector agropecuario $10 \%$ (1 empresa), sector comercial $10 \%$ (1 empresa), sector construcción 40 \% (4 empresas), sector industrial $30 \%$ (3 empresas), sector servicios $10 \%$ (1 empresa). El sector que se destacó en la creación de pequeñas empresas fue el de la construcción.

\section{Discusión}

Se presentará el análisis para cada figura en las dos secciones correspondientes.

\section{Aspectos generales de la ley del primer empleo en las pequeñas empresas creadas en el año 2013 de la ciudad de Sogamoso}

Los resultados de la Figura 1 muestran que en la ciudad de Sogamoso el sector de la construcción ha cobrado gran importancia durante los últimos años y, por ende, ha sido uno de los grandes generadores de empleo, aunque a veces estos solo sean temporales. Además, este sector se ha ubicado como uno de los principales motores e impulsadores del crecimiento no solo de la ciudad de Sogamoso sino del país. Según el Ministerio de Educación (2016), desde el año 2000 este sector ha incrementado su participación en el PIB total en cerca de 2.35 puntos porcentuales.

Por otra parte, la Figura 2 indica que el número de personas que laboran actualmente en las empresas corresponde al rango consignado en la legislación colombiana (Ley 905 de 2004), perteneciente a la pequeña empresa que cuenta con una planta de personal entre once (11) y cincuenta (50) trabajadores. Activos totales por valor entre quinientos uno (501) y menos de cinco mil (5000) salarios mínimos mensuales legales vigentes. El $60 \%$ de las pequeñas empresas afirmó tener una planta de personal de 11 a 20 trabajadores; esto debido a las condiciones de la actividad que realizan y el panorama económico de la ciudad, por lo cual no es necesario contratar mayor personal para cumplir el límite según lo establecido por la ley.

Por otro lado, los resultados arrojados por la Figura 3 expresan que si bien es cierto que la ley del primer empleo ha permitido la creación de un número de empleos significativos, no obstante este esfuerzo aún sigue siendo pequeño frente a los grandes retos que factores como la falta de experiencia generan frente a un mercado laboral que día a día se hace más competitivo. La experiencia se ha convertido en un factor trascendental a la hora de emplearse. Por un lado, este factor ha sido una barrera para los jóvenes en busca de su primer empleo, pero, por otro lado, la mayoría de las empresas no están dispuestas a correr el riesgo de tener personas inexpertas en los procesos y actividades que se realicen dentro de la misma. Frente a este dilema es determinante el rol que juega la academia en las oportunidades de práctica y proyectos de campo que les ofrecen a los estudiantes, dado que la academia debe estar actualizada y articulada con lo que sucede en el mundo laboral para tener un conocimiento profundo tanto de sus fortalezas y debilidades, así como de sus oportunidades y amenazas.

Según lo expresado por la Figura 4, todas las empresas aseguraron tener conocimiento de la ley del primer empleo. Aunque parezca positivo existe una gran diferencia entre escuchar y entender realmente una ley con todas sus implicaciones (beneficios, sanciones, oportunidades, desventajas).

De acuerdo con los resultados de la Figura 5, las pequeñas empresas fueron informadas sobre la ley del primer empleo principalmente por 
la televisión, seguida de la radio, la internet y la prensa. De esta manera, sigue siendo la televisión el medio principal para informar a los ciudadanos sobre diversas leyes que se instituyen independientemente del efecto que generen. Asimismo, la radio juega un papel importante especialmente para las personas mayores de edad. A su vez, la internet juega un rol fundamental en la comunicación de información debido a la era tecnológica que el mundo vive, lo cual ha permeado la interconexión entre todas las edades sin excepción alguna, es actualmente el medio más rápido y de fácil acceso.

Por otro lado, la Figura 6 muestra la acogida a la ley del primer empleo por parte de las pequeñas empresas de la ciudad de Sogamoso. El resultado es de $50 \%$ / $50 \%$. El $50 \%$ de las pequeñas empresas que se acogió a la ley afirmó que fue una oportunidad importante a la hora de crear la empresa en términos de beneficios especialmente tributarios y de simplificación de trámites, así como de contratación de personal. Dentro de los factores que argumentan que el $50 \%$ de pequeñas empresas no se haya acogido a la ley se encuentran: la falta de asesorías a los diferentes empresarios para acogerse a dicha ley, con el fin de mostrar los pro y los contra; la apatía de varios empresarios para acogerse a la ley y cumplir la normativa de emplear a diferentes sectores de la población; la falta de compromiso por parte de diferentes entes públicos y privados para incentivar a los empresarios a cobijarse bajo dicha ley; por último, el miedo a emprender o crear empresa, ya que este factor era una opción factible para acogerse a la ley, por ende, lograr los beneficios que ofrecía la misma.

De la misma manera que la figura anterior, la Figura 7 presenta un equilibrio por parte de aquellas empresas que reciben los beneficios tributarios. Claramente las empresas que están acogidas recibirán los beneficios y las que no, no los recibirán. Los beneficios que ofrece la ley del primer empleo son diversos, van desde programas especiales para crédito y microcrédito que facilitan la financiación de los proyectos de las empresas, hasta beneficios tributarios como el pago de forma progresiva de impuestos, parafiscales, matrícula mercantil y su renovación. Todo esto aplica para las nuevas y pequeñas empresas que se formalicen o que se creen a partir de la vigencia de la presente ley. Ahora bien, las empresas que afirmaron acogerse a la ley y recibir los beneficios, deben cumplir con los requisitos que la ley demanda, pero al parecer muchas de estas evaden de manera sigilosa las obligaciones con tal de recibir los beneficios, lo que las hace acreedoras de sanciones. Entes como la DIAN (Dirección de Impuestos y Aduanas Nacionales de Colombia) y UGPP (Unidad de Gestión Pensional y Parafiscales) se proponen controlar y sancionar a las empresas que no reúnen los requisitos para estar accediendo a los beneficios de la Ley 1429 de 2010.

De acuerdo con los resultados arrojados por la Figura 8, el $40 \%$ de las pequeñas empresas (4 empresas) asegura emplear a personas jóvenes o recién egresados de su carrera profesional. Aunque este porcentaje podría parecer satisfactorio, al ahondar un poco más en la respuesta dada por estas empresas, se descubrió que en su mayoría corresponden o son aprendices del Sena; no obstante, algunas empresas sí contratan jóvenes egresados de diferentes universidades de la ciudad, pero en menor número comparado con los del Sena. Lo que se observa es que muchas empresas creen que contratar personas del Sena es algo muy noble de su parte, cuando en realidad según la Ley 789 de 2002 en su artículo 32 y 33, las empresas 
se encuentran obligadas a la vinculación de aprendices, «empresas privadas, desarrolladas por personas naturales o jurídicas, que realicen cualquier tipo de actividad económica diferente de la construcción». "Las empresas que tengan entre quince (15) y veinte (20) trabajadores tendrán un (1) aprendiz». Por otra parte, el $60 \%$ de pequeñas empresas (6 empresas) aseguraron no contratar este tipo de personal principalmente por la falta de experiencia, además de la carencia de conocimiento o especialización en el área respectiva de trabajo.

Por otra parte, la Figura 9 muestra que el rango de jóvenes menores de 28 años contratados por las empresas en un $60 \%$ se encuentra entre 1 a 10 . Solo el $20 \%$ de las pequeñas empresas asegura tener entre 21 a 30 jóvenes laborando en las mismas. Mientras que un $20 \%$ no cuenta con jóvenes laborando en sus empresas. Se percibe por parte de las pequeñas empresas desconfianza a la hora de emplear este segmento de la población principalmente por la falta de experiencia, además de que en ocasiones los conocimientos adquiridos en la academia no concuerdan con las tendencias y el panorama actual que vive el sector empresarial tanto nacional como internacional.

Según los resultados de la Figura 10, se refleja un tipo de pensamiento erróneo por parte de las empresas hacia las personas en situación de discapacidad, debido a que el $90 \%$ de estas no contrata este segmento de la población, específicamente por creer que una persona en esta condición no puede desempeñar adecuadamente algún trabajo o que de hacerlo no lo haría con los mismos criterios de calidad de aquella que no tiene discapacidad. Sin embargo, está comprobado que muchas empresas que le han dado la oportunidad de laborar a este tipo de personas han descubierto las potencialidades que tienen, de acuerdo con sus capacidades pueden desenvolverse en el mundo laboral hasta mucho mejor que una persona sin discapacidad. No obstante, más allá de que en los últimos años el país haya avanzado en el diseño de políticas públicas enfocadas a la inclusión de las personas con discapacidad y de que existen numerosos beneficios tributarios para las empresas que vinculen laboralmente a estas personas, aun así, este tema seguirá siendo complejo y de larga trayectoria por emprender.

Los resultados arrojados por la Figura 11 de las mujeres mayores de 40 años que laboran en las pequeñas empresas, indican que al igual que los jóvenes, es un segmento vulnerable y afectado por el desempleo, puesto que el $60 \%$ de las pequeñas empresas ( 6 empresas) aseguró no tener laborando a ninguna mujer mayor de 40 años en la empresa. Aunque este segmento posea experiencia, factores como la edad y la falta de especialización en áreas dentro de la empresa hace que sea rechazado, mientras que otros son rechazados por estar sobrecalificados. Pese a este dilema los empresarios deberían de ser más conscientes a la hora de brindar oportunidades de empleo tanto a jóvenes como mujeres mayores de 40 años, entre otros, con el fin de contribuir al desarrollo y crecimiento económico de la ciudad.

Por otra parte, la Figura 12 muestra que el $100 \%$ de las pequeñas empresas está completamente de acuerdo con que la ley del primer empleo ha sido eficaz para ayudar a la población juvenil a encontrar su primer empleo, aunque algunas de estas no sean parte de la cadena de generación de empleo, ya que no están acogidas a la ley, por ende, no cumplen con lo que esta demanda; lo que redunda en una situación bastante irónica. Por otro lado, para el Gobierno colombiano más exactamente para el Ministerio del Trabajo la ley ha sido todo un éxito. Según el Ministerio del Trabajo 
(2012), tras el primer año de vigencia, la Ley de Formalización y Generación de Empleo (Ley 1429 de 2010) demostró ser un excelente instrumento para mejorar la situación laboral del país, con beneficios para cerca de 45000 empresas y 400000 jóvenes menores de 28 años. Sin embargo, el desempleo de la población juvenil es una realidad innegable que cada día va en aumento debido a múltiples factores ya sean sociales, económicos, políticos, culturales, entre otros. Según la OIT (Organización Internacional del Trabajo, 2015) de su informe Perspectivas sociales y del empleo en el mundo - Tendencias 2015, la tasa mundial de desempleo es de alrededor de $6 \%$ y no se achicará en el corto plazo, indica la Organización. En 2014 había 201 millones de personas sin empleo, 1.2 millones más que en 2013. Se espera que esa cifra aumente a 212 millones en 2019.

Por último, la Figura 13 muestra que las pequeñas empresas consideran necesario adoptar nuevas medidas eficientes y eficaces de carácter obligatorio en cuanto a la reducción del desempleo en la población juvenil. Asimismo, expresaron que es una tarea de trabajo conjunto no solo de los empresarios, sino de los gobiernos, academia y sociedad, destacándose el Gobierno a la hora de establecer políticas y estrategias contundentes que disminuyan los índices de desempleo y generen oportunidades equitativas para todos. El rol que juega la academia es fundamental ya que esta se encarga de preparar o capacitar a los jóvenes para enfrentarse al mundo laboral, por ello, es preciso que estén al tanto de las necesidades de la comunidad empresarial hoy y no hace cinco años, de esta forma estar a la vanguardia, ser competentes y marcar la diferencia. Finalmente, William Reese Director de la Fundación Internacional de la Juventud, en el informe de la OIT presentado a la ONU en el mes de febrero del año 2015 expresó: «Todos los niveles de la enseñanza tienen que ser más inteligentes y enseñar habilidades académicas mediante pasantías [...] para ayudar a los jóvenes a aprender cosas sobre el trabajo que no podrían obtener en un salón de clases [...] Queremos que los jóvenes consigan empleo y lo mantengan. Cuando la clase media prospera, las democracias florecen».

\section{Cumplimiento de los objetivos específicos de la presente investigación}

Los resultados arrojados por la Figura 14 indican que el sector de la construcción sobresale en la acogida y aplicación de la ley del primer empleo, seguido del sector comercial, industrial y de servicios. Según lo expresado por estas empresas pertenecientes a dichos sectores además de conocer la ley, se encuentran bajo su cobertura y afirman cumplir la normatividad que esta exige. Sin embargo, la realidad de si cumplen o no con todo lo exigido en la ley se examinará en la Figura 15 . El sector de la construcción destaca sobre los otros sectores. De acuerdo con el Observatorio Económico Boyacá (2014) en el año 2013 se otorgaron 1549 licencias de construcción, 3.1 \% más que el año anterior. El área aprobada fue de $720258 \mathrm{~m}^{2}$, superior en $14.7 \%$ al 2012 cuando registró $627990 \mathrm{~m}^{2}$. El área licenciada fue de $633752 \mathrm{~m}^{2} ; 27 \%$ más que en el 2012 y equivalente a $498925 \mathrm{~m}^{2}$; el mayor número de licencias concedidas fue para Sogamoso (38.5\%), seguido de Tunja (28.2 \%) y Duitama (23.2 \%). Por otro lado, las empresas que aseguraron no estar acogidas y por tanto no aplicar la ley del primer empleo se basan en la falta de información frente a la misma, sumado a la apatía y desinterés con respecto a estos temas. 
Los resultados de la Figura 15 muestran que el $20 \%$ de pequeña empresa ( 1 empresa) del sector de la construcción parece cumplir cabalmente la ley, por otro lado, el $40 \%$ de pequeñas empresas ( 2 empresas) lo hace parcialmente, mientras que el $40 \%$ de pequeñas empresas restantes (2 empresas) no cumplen la ley, pese a recibir los beneficios que esta ofrece. La situación es preocupante debido a que se observa la falta de gestión a través de entes como la DIAN (Dirección de Impuestos y Aduanas Nacionales de Colombia) y la UGPP (Unidad de Gestión Pensional y Parafiscales) para vigilar y sancionar a las empresas que no cumplan la normatividad.

El artículo 49 de la Ley de Formalización y Generación de Empleo (Ley 1429 de 2010, Ministerio del trabajo) señala las sanciones por el suministro de información falsa. Quienes suministren información falsa con el propósito de obtener los beneficios previstos en los artículos 4, 5, 7, 9, 10, 11 y 13 de la presente ley deberán pagar el valor de las reducciones de las obligaciones tributarias obtenidas, y además una sanción correspondiente al doscientos por ciento $(200 \%)$ del valor de tales beneficios, sin perjuicio de las sanciones penales a que haya lugar.

Por último, los resultados de la Figura 16 muestran que tanto el sector de la construcción (4 empresas) como el sector industrial (3 empresas) son los impulsores de la economía de la ciudad, hecho que se evidencia a través de la creación de empresas en dichos sectores. La mayor preocupación se presenta en el sector agropecuario, dado que no se presentan avances importantes, a pesar de poseer un campo fructífero y con bastantes recursos por aprovechar, estos no se gestionan y administran eficientemente.
De la presente investigación, se concluye que la ley del primer empleo ha sido un avance importante para el país, por ende, para el departamento de Boyacá y la ciudad de Sogamoso, sin embargo, por sí misma no es suficiente para estimular la creación de empresas en condiciones de formalidad empresarial y laboral. Para ello es necesario trabajar en la sostenibilidad de las empresas, si existen empresas más formales, habrá trabajadores más formales, lo cual es un elemento central para mejorar las condiciones en el mercado laboral. Si bien es cierto uno de los eternos círculos viciosos difíciles de romper es que a los recién egresados no se les brinda mayores oportunidades laborales por no tener experiencia y nunca pueden acreditar experiencia porque las empresas no les ofrecen la oportunidad de trabajar, la respuesta a este dilema por parte de algunos tanto empresarios como estudiantes se logra aprovechando las pasantías, ya que estas son situaciones decisivas donde se pueden revelar aptitudes y capacidades que en algunas ocasiones permite quedarse con el puesto de trabajo.

Asimismo, es primordial invertir en la educación financiera y empresarial de los jóvenes con el fin de impulsar la creación de empresa para que el día de mañana puedan generar empleo en vez de demandar trabajo.

Por último, vale la pena preguntarse ¿el desempleo juvenil es un fenómeno de oferta? Algunas empresas aseguran que este es un aspecto a evaluar dentro de toda esta problemática, debido a que en ocasiones muchos jóvenes no están dispuestos a aceptar el primer empleo que se les ofrece debido a la exigencia en los salarios, así pues, al contar con el apoyo económico de sus familias deciden quedarse sin trabajar $y$ a la espera de conseguir un empleo más acorde con sus expectativas y remuneración adecuada. Por lo que pasan meses sin trabajo y cada 
vez la situación se torna complicada. Frente a este problema se presentan dos opciones: perseverar o desistir. Cada persona elegirá el camino a seguir de acuerdo con su criterio.

«El costo de no hacer nada, de dejar que el desempleo a largo plazo crezca y que los jóvenes pierdan contacto con la sociedad, sería mucho mayor", dijo Ryder (Director General de la Organización Internacional del Trabajo).

\section{Agradecimientos}

A Dios, el dador de la sabiduría, por ser mi guía, fortaleza y permitir que dentro de sus planes llevara a cabo la presente investigación. A mi familia, por apoyarme de manera incondicional en todo lo que me he propuesto. A la profesora Claudia Hernández, directora del Semillero de investigación, por su gran colaboración y acompañamiento en todas las etapas de la investigación. A la profesora Nancy Guerra, por compartir sus conocimientos y aportes valiosos en la investigación. A todas las pequeñas empresas creadas en el año 2013 de la ciudad de Sogamoso (Boyacá), por abrirme sus puertas para suministrar la información correcta y acorde con la investigación.

\section{Referencias}

- Boletín del Observatorio del Mercado de Trabajo y la Seguridad Social $n^{\circ}$ 13. (2011). ¿La Ley 1429 de 2010 ha formalizado el Empleo en Colombia? Recuperado de http://190.7.110.123/pdf/6_derechoSeguridadSocial/boletines/Boletin13Enero23.pdf

- Congreso de Colombia. (diciembre 29 de 2010) Ley de Formalización y Generación de
Empleo [Ley 1429 de 2010]. Recuperado de http://wsp.presidencia.gov.co/Normativa/ Leyes/Documents/ley142929122010.pdf

- Ministerio de Educación Nacional de Colombia. (2016). Educación técnica y tecnológica Construcción. Recuperado de http://www.mineducacion.gov.co/1759/w3-article-299750.html

- Ministerio del Trabajo. (2012). Abecé de la Ley de Formalización y Generación de Empleo «ley de primer empleo». Bogotá: Ministerio del Trabajo. Recuperado de https://goo.gl/Wy1JXj

Observatorio económico Boyacá. (2014). Sector de la Construcción. Recuperado de Observatorio Económico- Boyacá, http://www.boyaca.gov.co/economico/ sectores-economicos/sector-construccion.

- Organización Internacional del Trabajo (OIT). (2013). El Desempleo mundial aumenta nuevamente, pero con grandes diferencias regionales. Recuperado de http://www.ilo. org/global/about-the-ilo/newsroom/news/ WCMS_202333/lang--es/index.htm

\section{Bibliografía complementaria}

- Boletín del Observatorio del Mercado de Trabajo y la Seguridad Social. (2012). Universidad Externado de Colombia. Recuperado de https://www.uexternado.edu.co/wp-content/uploads/2017/01/boletin13-nuevo.pdf

Butler, P.J. (2015). Desempleo juvenil real sería muy superior a cifras de la OIT. Inter Press Service. Agencia de noticias. Recuperado de http://www.ipsnoticias.net/2015/02/desempleo-juvenil-real-seria-muy-superior-a-cifras-de-la-oit/ 
- El Tiempo, Casa Editorial (2014). Coyuntura / Hay Que incentivar La formalización de las pymes. Recuperado de http://www.portafolio.co/detalle_archivo/DR-111809

- Freire, E., Perfetti, M., Silva, D., (2014). Resumen ejecutivo. MERCADO LABORAL DE LA JUVENTUD (14 a 28 años). Trimestre móvil noviembre 2013 - enero de 2014. Bogotá: DANE. Recuperado de https://www.dane. gov.co/files/investigaciones/boletines/ ech/juventud/RE_trim_nov_ene14.pdf

- Hurtado, C. (2013). Ni estudias ni trabajas: la tragedia del desempleo juvenil. Recuperado de http://www.kienyke.com/economia/ desempleo-juvenil-colombia.
- Tissot, V. y Olano M. F. (2011). Impacto de la ley de primer empleo. Portafolio. Recuperado de http://www.portafolio.co/economia/ finanzas/impacto-ley-primer-143438

UAE. DIAN. Coordinación de Estudios Económicos. (2013). Primer informe sobre la aplicación de la Ley 1429 de 2010, Cifras y estimación del Costo fiscal año gravable 2011. Cuaderno de Trabajo nro. 49. Recuperado de https://goo.gl/4ggkbP 